\title{
Exploration of Teaching Modes of Children Creative Rhythmic Activities
}

\author{
Yuan Lin \\ College of Teacher Education, Kunming University, Kunming, 650031, China
}

\author{
Keywords: Children. Creative Rhythmic Activities. Teaching Mode
}

\begin{abstract}
Children creative rhythmic activities have important educational value and status for music education in kindergarten, and effective teaching activity mode is an important guarantee to achieve its educational value. Through years of research and exploration, we have found that the creation of activities environment in favor of young children to explore music, improvement of specific ways of teaching activities and perfect of its design and other aspects can help to improve their interest in learning and initiative, as well as sensibility, creativity and expressiveness to music, gaining unexpected results.
\end{abstract}

\section{Introduction}

Creative rhythmic activities refer the activities expressed by rhythmic creative body movements in music accompanied, and body movements of children creatively expressing external morphology and state of motion for specific things on the basis of self-observation, imitation, understanding and imagination. Music educator of children Carl Orff said, music education begins action. Indeed, body movements and music are often inextricably linked in music activities of kindergarten; action is the most direct and natural means for children to express and reproduce music. Creative rhythmic activities can meet the needs of participation and exploration of children in music to obtain perception, experience and expression of melody, rhythm, strength, speed and other musical sensibility, expressiveness and creativity; as well as better promote coordination development of physical exercise capacity and movement of children, thereby improving ability of children to use limbs for musical performance and the development of integrated aesthetic musical qualities.

\section{Creation of activities environment in favor of children to explore music}

Creative environment has a very important role in the development of creativity and creation process; in children development, only creative environment can develop creative personality. The concept of "musical exploration" deriving from constructivism theory, emphasizing to provide free and open learning environment; exploration classroom must have rich and diverse exploration media materials, so that children can freely choose to try musical instruments or various props of their own interest. Such entertaining way of learning can make children love the resources within the activities environment, in addition, the actual operation and observation make more profound impression and better learning results.

Meanwhile, interest is the motivation for children to participate in musical activities; musical materials are the basis for children to participate in activities; and a wide variety of operating materials are the source for children to stimulate interest. Therefore, a creative children teacher will provide variety of musical materials, instruments and even materials in combination of art to carry out a variety of musical activities. Types of music provided for children can involve simple early childhood music, or simple adult music, such as: hymns, folk, country music, pop music, classical music, etc. Try to select some favorite tunes for teachers to match the activity design, because teachers' happy mood can easily affect the mood of children. Carefully arrange musical activities and arrange the free or spontaneous activities in very structural way, but such structural courses must be arranged when children can concentrate on learning.

In addition, design skills have to be carefully used in course design to achieve perfect teaching, and the value of the teaching plans is just as a consultant. Before implementation of creation thinking 
teaching, if teachers can master strategies of many experts and scholars and select appropriate strategy as the reference for teaching design plan, the goal of creation thinking teaching can be achieved.

\section{Perfect of Design of Teaching Activities}

\section{Design rhythmic activities by using music appreciation activities}

It is an important goal of music appreciation courses using music as medium and stimulate imagination of children. Music has rich moving power that can inspire infinite imagination of children, while express their own unique ideas according to different life experience - older children can be guided to use words to express; and younger children can be encouraged to use spoken or action to render. The contents of five-stage music appreciation courses designed by the author are as following, which can be used as reference of activities guide for teachers:

Introduce children to listen to "Aquarium" music taking "Little Bubbles' Trip" for example, and the entire teaching process can be illustrated as follows: imagination hint $\rightarrow$ listening $\rightarrow$ feeling $\rightarrow$ listening again $\rightarrow$ performance and creation.

\section{Imagination hint}

1). Teachers tell kids this is a music in description of "Aquarium".

2). Ask the children: "What are the things in the aquarium; which things can move and which things can not move? ? "

3). Ask them: "In the music you have heard, which sounds may be the sounds produced within the aquarium?"

4). Tell the children that there may be some sounds of musical instrument, please listen to carefully.

\section{Listening}

Play the "Aquarium" music by the teacher; allow children to listen to music, and guide them to make association with the problems above.

\section{Feeling (Express feelings )}

After the children finish listening to music, encourage children to use their imagination for oral presentation of their feelings. When teachers guide, pay attention to focus on stimulate imagination of children, avoid giving too many hints, or implying the results or answers expected to obtain.

\section{Listening again}

Teachers should proper guidance against the results expressed by children, and provide the part children failed to listen or missed or ask them to listen more intently.

\section{Performance and creation}

According to the results imagined by children, guide children to perform with movement, expression, dance, painting or playing patterns, and guide them to make more unique performances.

\section{Design rhythmic activities using music graph}

The music assisted teaching activities refer that help learners to master the content of music by transforming music into graph, and figure out the part how the graphs use in some music teaching from graphic design elements of "point, line, surface". Music is the art of time, so does painting to space; although both media expressed have great difference, their artistic essences have inextricably accommodative. Namely melody to lines; speed and rhythm to rhythm of graphs; sound to space; timbre to light and texture; musical form to layout, strength to color. Thus, music and painting has close relationship.

Taking "wind up" for example, make unified whole and analysis from teaching objectives, programs and principles:

\section{Teaching objectives}

1). Develop abilities to look for rule of musical variation, understand the changing state of many things in strong wind, and combine.

2). Explore the expression with actions and limbs; develop abilities to imagination and creation.

3). Promote communication with others. 
4). Using symbols or patterns to show graph; create another form of composing music method which is more in line with needs of children.

5). Increase the chance of division of labor.

\section{Teaching programs}

1). Previously collect various drawings, poetry, nursery rhymes and stories to stimulate the children to think and imagine.

2). Give simple "rhythm box" exercises for training concentration on graphs to children.

3). Guide "sound creation exercise"; describe the use of graphs and symbols; perform curvature of lines, sound level, length, size, and the time of music.

4). Guiding based on theme stories or poems, work together to find a variety of sounds having in common with theme, and then take picture away, lists the possible phenomena.

5). Create sound-type, instrument or voice types by the children themselves.

Design principles

1). Suitable for children in top class of kindergarten or lower primary.

2). Acceptance and children participating in the activities must know how to control a variety of musical instruments.

3). Contents required to perform should be more narrative, dramatic, avoiding too much interpretation.

4). Require children use more imagination, to improve the quality of creation.

\section{Design rhythmic activities using musical dramas activities}

It is quite popular in recent years for combination of music and other artistic patterns, namely integration of music and rhythm movement games as the basis for design. The essence of musical dramas is actually a game, mainly through the dramas as a way of teaching, regarding the activity as a game and the classroom as the entertainment place; the children freely create, handmade costumes, props and personally play the roles in the drama. It does not care how to show, while focuses on the performance of emotion and imagination; it provides opportunities for children to self-making, directing and acting and freedoms for fully developing; also encourage children to do impromptu, pure and natural performance, and teachers often plays the role of counseling in the creative dramas activities.

A content-rich, interesting children musical drama not only can stimulate active ideas of children, freely matching props, backgrounds and clothing, but also better to be able to fully demonstrate physical activities and use of stage and space; and must perform coordinating with music. Thus, musical performances can probably develop various abilities of children.

If a troupe consisting of kindergarten's teachers perform, there is need to consider to do its job well before the show. Presentation of children dramas generally may include job scope; various kindergartens and human resources can make appropriate adjustment and allocation as needed.

\section{Design rhythmic activities using picture book activities}

Bringing literature textbooks of children in the unit activities of kindergarten and developing curricula in different areas based on the theme is the popular recent trend for early childhood education. In fact, in terms of using hidden organizational mode in picture books, it will not only help children develop reading confidence, as well as the potentiality of speaking art, but also cultivate abilities to independent reading or sharing reading with others as well as development of a variety of artistic abilities through various interacts in courses.

In theme activities, "Busy Spider", "Rainbow Fish", "Story of the Moon" and "Hungry Caterpillar" and so on are the examples using picture books of children in music activities. We try to use a tome picture book of children as a example of activities. Activities include the activities of the art, society, science, mathematics, picture books helping the music teachers to use printing, and curricula design of integration art, humanities and natural areas, hoping to encourage teachers to make creative ideas, make meaningful connection with music rhythm movements, or develop extension activities related areas by means of this article. In addition to bring the development of children in language by using literature teaching activities, if they can combine study in other fields, it not only can enrich the ductility of materials, but also achieve all-round development of children. 
When we use picture books for teaching, we can design individual theme activities according to interests of children and your understanding to children. Three to seven themes activities can be extended according to the contents in picture books familiar to children.To shape basic reading experience of children, build their confidence to books first. It is the effective method to build reading confidence for children by using the group or team teaching method to let them have chance to share fun brought by stories.

Teachers can design themes of stories related painting, modeling, dramas, music, singing games, poetry and rhythmic activities, etc. For example: after finish the story of "Rainbow Fish", teachers can play rhythm activity of simulation modeling of fish body with children or let the children paste colorful sequins on fish model figure, etc. or let children paint on black paper by using fluorescent pigment. The story will be more interesting if add background music.

Such as taking "Freight Train" (Crews, 1993) as a example, it is a very special large-type book for children, which can let the teacher have better teaching quality, and feel the joy of teaching. Large-type books for children can expand literature life of children as well as have positive experience of literary reading. Especially, large words and images can allow all children in the classroom share their beauty and story plots, and also have a long memory to the poetry and fun in the book.Especially in the group learning activities, teacher's guiding reading and sharing and discussion can virtually rich oral expression ability for children.

"Freight Train" and means of transport and travel related, it is also book on color. Teachers have the responsibility to closely link the part of the living experience interested by children with the contents of the book together, at the same time, expand the reading scope into other fields related to children living experience. Outdoors or at playground, let the child to experience feelings such as walking around, passing some things and moving around as far as possible; encourage children to climb, jump, run, slide on the ground or set up a long strip with limbs, pretending to produce squeaky voice when train climb hillside during the activity; fast move the train; let the train turn around the curve, straight line or arc line. Let the children imagine freely as possible as they can, and make the rhythm activity of the body.

In short, it is very important to research and explore effective teaching mode in creative musical rhythmic teaching activities, which is directly related to the education and development of children.

Only constant practice and exploration can have more and better teaching ways to help us improve the quality of teaching .

\section{References}

[1] Xu Zhuoya: Kindergarten Music Education, Beijing, People's Education Press, 2004

[2] Huangjin: Preschool Music Education, Shanghai, East China Normal University Press, 2006

[3] Li Mingdeng: Kindergarten Musical Enlightenment Activities, Wuhan, Hubei Fine Arts Publishing House, 2011

[4] Gao Hongxing: Pre-school Children Art Education, Beijing, Science Press, 2012

[5] Xu Zhuoya: Rhythmic Activities, Nanjing, Nanjing Normal University Press, 2001

[6] Huang Liya: Creative Musical Power Games, Psychological Press, 2009 